\title{
Attention on Aromatic Rice Production May Create a New Era on Export Income in Bangladesh: An Opinion
}

ISSN: 2637-7659

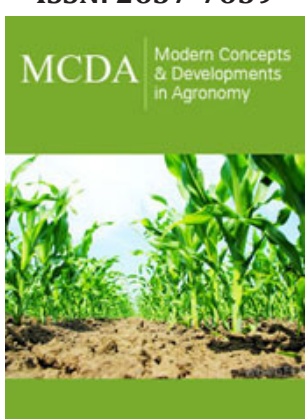

*Corresponding author: Rajesh Chakraborty, Department of Agronomy, Sher-e-Bangla Agricultural University, Dhaka-1207, Bangladesh

Submission:

Published: 眥 May 04, 2020

Volume 6 - Issue 2

How to cite this article: Rajesh Chakraborty. Attention on Aromatic Rice Production May Create a New Era on Export Income in Bangladesh: An Opinion. Mod Concep Dev Agrono. 6(2). MCDA. 000631. 2020

DOI: 10.31031/MCDA.2020.06.000631

Copyright@Rajesh Chakraborty, This article is distributed under the terms of the Creative Commons Attribution 4.0 International License, which permits unrestricted use and redistribution provided that the original author and source are credited.

\author{
Rajesh Chakraborty* \\ Department of Agronomy, Sher-e-Bangla Agricultural University, Bangladesh
}

\section{Introduction}

Aromatic rice is called due to its novel 2-Acetyl-1-pyrroline (2-AP), which is also named as fragrant rice for its magnificent aroma [1]. Upon cooking the aromatic rice gives a pleasant flavor, aroma and taste in our mouth and nose. Mainly the aromatic rice is eaten for its special aroma not for starch granule as in plain rice. The Peoples of most Asian countries are more interested to intake the fragrant rice in daily food, and in different occasion as plain aromatic rice and sticky rice. The long, slender, sticky and softness are the most crucial traits for fragrant rice [2], like Jasmine of Thailand and Basmati of Indian sub-continent. The peoples of Bangladesh choice a long, slender and dry trait for aromatic rice after cooking and interested to make different delicious foods stuffs. Recently, Bangladesh has started a new journey to produce some aromatic rice by keeping the export goals and exported some rice in Sri Lanka. In Bangladesh, Sharpers, Sunamgonj, Dinajpur, Rangpur are getting attention due to its edaphic condition as special areas for growing aromatic rice and there have some local and released cultivars and varieties. Among these kalojira, radhunipagol, sarnolota, tulsimala, ciniatob, khaishanne etc. as local cultivars and BRRI dhan34, BRRI dhan50 and BRRI dhan 80 etc. as variety are much prominent.

\section{Limitation}

However, in spite of having so much attractive traits in aromatic rice, the growers of Bangladesh has not been able to produce targeted amount of aromatic rice to export due to production and storage limitation. The climatic factors like temperature, humidity, rainfall etc., and managerial factors like soil nutrients, growing condition, growth regulators, harvesting time, drying methods, drying periods, storage condition, storage containers etc. might be mediated the aroma content in fragrant rice. Lacking of processing policy and plant are also a most limiting factor for aromatic rice storage and expansion in Bangladesh. The government of Bangladesh did not make any crop incentives yet on aromatic rice cultivation over plain rice for the growers. The aim of this opinion article is to explore the major production and storage techniques viewed from my observations to improve the retention of aroma in fragrant rice.

\section{Approaches}

Upon follow the strategies by which we could be able to improve the total aroma content in rice grain and knowledge's for cultivation of aromatic rice as a whole.

\section{a) Field approach}

Basmati rice has great interest as aromatic rice in Indian sub-continent. But from my observation it can be said that, Radhunupagol, local fragrant rice cultivated specially in Dinajpur and Rangpur district in Bangladesh for its pleasant aroma and flavor which could be usable as substitute for Basmati rice. The application of minimum tillage may increase only 
the amount of aroma in rice but more ploughing may increase both the aroma and yield of aromatic rice [3]. The stages of rice plant might be influenced the content of aroma in rice. Among different stages of rice, the aroma was found highest in seedling stage due to its more green leaves and the aroma was also found more in grain filling stage. Findings demonstrated that rice plant treated with growth regulators inhibited the metabolic processes associated with the formation of volatile compounds like 2-AP. In grains, 2-AP content could be increased by the application of some water as irrigation at tilling, booting, and grain filling stage; the observation is supported by [4]. Studies showed that salt stress can increase 2-AP content in grains [4]. So this knowledge can be usable in saline prone areas of Bangladesh where salinity is a major problem for normal crop production. Grain aroma content of aromatic rice could be improved by applying additional $\mathrm{N}$ at booting stage while considering the amount of $\mathrm{N}$ fertilizer added [5]. From my observations it might be said that, application of Manganese (Mn) and ( $\mathrm{Zn}$ ) had a positive effect on 2-AP content in aromatic rice. From the finding of [4] it may be said that, 2-AP content was increased by moderate concentration of lanthanum (La). The application of silicon could increase the content of grain aroma [6]. We found that sometimes the induction of moderate drought stress could increase the aroma content in rice in field during grain filling stage. We have seen that, at the areas of moderate shad in field the aroma content was higher than that of sunny areas at the later stage of rice plant. Research of [7] also supported that during grain filling period, shading significantly improved the 2-AP content in aromatic rice grains.

\section{b) Harvesting and drying approach}

The farmers of Bangladesh conventionally harvest the rice grains at long after the optimum time of harvesting by keeping the views of full maturity. As a result, due to long time staying in field naturally the aroma of grains is lost by internal field respiration by excessive temperature from sunlight. Then the aroma of grains are showed loser in concentration during storage and marketing which resulted lowest economic returns for growers. So, the aromatic rice grains must be harvested at optimum time of harvest (at 70$80 \%$ maturity for reducing the opportunity of aroma losses). High temperature during conventional semi-concrete floor/earthen floor drying system could reduce the concentration of 2-AP in Bangladeshi fragrant rice. So, an optimum drying temperature (10$15^{\circ} \mathrm{C}$ ) should be maintained for aromatic rice to store.

\section{c) Storage approach}

After drying the amount of rice aroma (2-AP) can be reduced upon storage due to internal respiration by moisture, temperate and relative humidity. Due to oxidation, rice grains with higher levels of moisture content reduced the 2-AP concentration more rapidly than the lower levels of moisture content. At 15 degree centigrade, 2AP can be maintained in higher amount than in ambient condition (25$35^{\circ} \mathrm{C}$ ). The amount of $2 \mathrm{AP}$ will be reduced by $50 \%$ even when using low temperature to dry fragrant rice and storing them in ambient condition compared to 15 degree centigrade [8]. The vacuum bag packaging increased the concentration of 2-AP in aromatic rice than polythene bag, gunny bag and cloth bag upon storage.

\section{Conclusion}

From this opinion article it can be concluded that if the growers of aromatic rice in Bangladesh is able to use these approaches so that they will get higher production of aromatic rice with higher pleasant aroma in grains after harvest and also in storage. Moreover they could purchase their rice grains with higher prices in local market and also cloud be exported surplus amount of production by meeting local demand and could take part in national economy as a great sector under Agricultural GDPs.

\section{References}

1. Routray W, Rayaguru K (2018) 2-Acetyl-1-pyrroline: A key aroma component of aromatic rice and other food products. Food Reviews International 34(6): 539-565.

2. Suwannaporn P, Linnemann A (2008) Rice-eating quality among consumers in different rice grain preference countries. Journal of Sensory Studies 23(1): 1-13.

3. Du P, Luo H, He J, Mao T, Du B, et al. (2019) Different tillage induces regulation in 2-acetyl-1-pyrroline biosynthesis in direct-seeded fragrant rice. BMC Plant biology 19(1): 308.

4. Ren Y, Ashraf U, He LX, Mo ZW, Wang F, et al. (2017) Irrigation and nitrogen management practices affect grain yield and 2-acetyl-1pyrroline content in aromatic rice. Applied Ecology and Environmental Research 15(4): 1447-1460.

5. Mo Z, Ashraf U, Tang Y, Li W, Pan S, et al. (2018) Nitrogen application at the booting stage affects 2-acetyl-1-pyrroline, proline, and total nitrogen contents in aromatic rice. Chilean Journal of Agricultural Research 78(2): 165-172.

6. Mo Z, Lei S, Ashraf U, Khan I, Li Y, et al. (2017) Silicon fertilization modulates 2-acetyl-1-pyrroline content, yield formation and grain quality of aromatic rice. Journal of Cereal Science 75: 17-24.

7. Mo Z, Li W, Pan S, Fitzgerald TL, Xiao F, et al. (2015) Shading during the grain filling period increases 2-acetyl-1-pyrroline content in fragrant rice. Rice 8(1): 9.

8. Borompichaichartkul C, Wiset $\mathrm{L}$, Tulayatun $\mathrm{V}$, Tuntratean $\mathrm{S}$, Thetsupamorn T, et al. (2007) Comparative study of effects of drying methods and storage conditions on aroma and quality attributes of Thai jasmine rice. Drying Technology 25(7-8): 1185-1192. 